\title{
A Correlative Study between Chronic Tonsillitis and Helicobacter Pylori
}

\author{
Abhishek Singh, ${ }^{1}$ Santosh Uttarkar Pandurangarao, ${ }^{1}$ Aravind Darga Ramchandra, ${ }^{1}$ Sridurga Janarthanan ${ }^{1}$
}

\begin{abstract}
$\underline{\text { Introduction }}$
Chronic tonsillitis is characterized by persistent inflammation of the palatine tonsils and seen commonly in patients attending ENT OPD. Bacterial infection is usually the cause but anaerobes and viruses may also be implicated. The possibility that tonsillar tissue possesses Helicobacter pylori or that H. pylori can colonize the palatine tonsils is explored.

Materials and Methods

Hundred patients aged between 5-50 years of either sex diagnosed with chronic tonsillitis undergoing elective tonsillectomy and willing to participate in the study were selected. Informed and written consent was taken from all the patients (in case of minor patients, consent was taken from parents). Specimen (tonsillar tissue) was harvested from the surgically removed tonsils and put through Rapid urease test. The results were analysed statistically using Chi square test and Unpaired t test and inference was drawn.

$\underline{\text { Results }}$

Amongst 100 patients, 61 (61\%) patients were females and 39 (39\%) patients were males. Helicobacter pylori could be detected in Chronic Tonsillitis in 64 (64\%) patients.

Conclusion

According to our study, Helicobacter pylori was found to be a common finding in cases of chronic tonsillitis. Even after regular treatment with antibiotics, the chances of getting acute infection in chronic tonsillitis still persist. We can try treatment for $H$. pylori and look for changes in recurrence of tonsillitis and also it can be tried in patients who are not willing/fit to undergo tonsillectomy.

Keywords

Palatine Tonsil, Tonsillitis, Tonsillectomy, Urease, Helicobacter pylori
\end{abstract}

\section{ABSTRACT}

$\mathrm{T}$ Tonsils are components of mucosa associated lymphoid tissue (MALT), which protect vulnerable mucosal surfaces. ${ }^{1}$ They are located in the tonsillar fossae between the anterior and posterior pillars formed by palatoglossus and palatopharyngeus muscles and the overlying folds of mucosa. ${ }^{2}$ They are a part of the Waldeyer's ring, a complete circle of lymphoid tissue surrounding the entrance to the gastrointestinal and respiratory tracts along with the lingual tonsils, the adenoids and the diffuse aggregates of pharyngeal submucosal lymphoid tissue.

1 - Department of ENT, JJM Medical College, Davanagere Rajiv Gandhi University Of Health Sciences

Karnataka

\section{Corresponding author:}

Dr Abhishek Singh

email: leoabhish@gmail.com
In health and disease, the organisms cultured from the tonsils are extremely variable, with recognized differences in bacterial flora retrieved from surface and from core samples. Group A beta haemolytic streptococcus (GABHS) is the most commonly identified organism from the surface of the tonsil. ${ }^{2} \mathrm{Up}$ to $40 \%$ of asymptomatic individuals will also have a culture positive for this organism. ${ }^{2}$ Other surface organisms include Haemophilus, Staphylococcus aureus, alpha haemolytic streptococci, Branhamella sp., Mycoplasma, Chlamydia, various anaerobes and a variety of respiratory viruses. ${ }^{2}$ In recurrent tonsillitis, the samples grew a range of organisms but predominant were Haemophilus influenzae and S. aureus. A mixed flora was also common.

Chronic tonsillitis is a common condition characterized by persistent inflammation of the palatine tonsils, and bacterial infection is usually the cause. There are chronic 
low grade symptoms affecting patient quality of life because of throat discomfort, and the production of white or yellow debris from the tonsillar crypts. Also, the patients have a feeling of low-grade ill-health. In children, historically, a very wide range of ailments including recurrent abdominal pain, general ill-health, failure to thrive and low body weight have been attributed to chronic tonsillitis. Conversely, removal of the tonsils has been claimed to result in increased growth rate and improvement in general health.

The gram negative bacterium Helicobacter pylori (H. pylori) resides in the human stomach, which was formerly considered a sterile environment due to its low $\mathrm{pH}$. Helicobacter pylori have been argued to be the commonest chronic bacterial infection in man. It has been detected in the mouth, in dental plaque and, more recently, in human faeces. ${ }^{1}$ Permanent $\mathrm{H}$. pylori infection is often acquired early in life. H. pylori, implicated as an etiological factor in duodenal ulcers and gastritis, induces the appearance of lymphoid aggregates (MALT) in the stomach. This organism is cytotoxic via a nitric oxide synthesis cascade. The possibility that tonsillar tissue possesses $\mathrm{H}$. pylori or that $\mathrm{H}$. pylori can colonize the palatine tonsils is explored.

Rapid urease test is a preferred method of examining tissue as it has high sensitivity and specificity. ${ }^{3} \mathrm{H}$. pylori produce urease, a hydrolase whose presence leads to any color change. The test well is filled with a urea containing gel and this is where the tonsillar tissue is inoculated and allowed to incubate. Urease produced by H.pylori will hydrolyze the urea in the gel. This will lead to accumulation of ammonium ion which causes a rise in the $\mathrm{pH}$ and this is detected by the $\mathrm{pH}$ indicators by a color change from yellow to pink or red. ${ }^{3}$

\section{Materials and Methods}

Data for this study was collected from the patients attending ENT outpatient department during the period from August 2017 to June 2018.

100 patients of either sex between 5 to 50 years of age diagnosed with chronic tonsillitis undergoing elective tonsillectomy under general anaesthesia and willing to participate in the study were selected. Informed and written consent was taken from all patients or their parents as applicable.

Tonsillectomy was done with dissection method and one tonsil per patient was collected. A $2 \mathrm{~mm}$ gross specimen was washed with normal saline. The specimen was then cut using a sterile blade and harvested. Specimen was then placed in a test well containing RAPID UREASE (GASTRO CURE SYSTEM RUT DRY TEST Batch No. A1060) and an initial color read at $0 \mathrm{~min}$. Subsequent color changes were read at 30 min, 6 hour and 24 hours. Any color change from the initial yellow color to either pink or red was recorded as positive. Any test well that remained yellow after 24 hours was recorded as negative. No readings were taken after 24 hours. All the data was recorded in proforma.

Statistical analysis: Qualitative data was represented in the form of frequency and percentage. Association between qualitative variables was assessed by Chi square test and Unpaired ' $t$ ' test. A ' $p$ ' value of less than 0.05 was considered statistically significant. Statistical analysis was done with IBM SPSS Version 22 for windows.

\section{Results}

The study was done on $100(\mathrm{n}=100)$ patients diagnosed with chronic tonsillitis.

The patients of age range $5-50$ years and of either sex were studied. Youngest patient was 5 years old with the oldest being 46 years. Mean age was 16.24 years. (Table I)

Most of the patients were between 5-10 years (38\%) and the least between 40-46 years (5\%). (Fig. 1)

Amongst 100 patients who underwent tonsillectomy, $61(61 \%)$ were female and 39 (39\%) were male (Fig. 2).

$100(100 \%)$ tonsillar specimens were subjected to RUT, out of which $64(64 \%)$ samples were found positive showing color change from initial yellow to pink/red within 24 hours and $36(36 \%)$ samples showed no color change i.e. tested negative (Table II)

On considering the results within individual age groups, most number of positive cases i.e. $26(68.42 \%)$ out of $38(100 \%)$ were found in age group of 5-10 years. This was compared within age groups and found to be 
Table I: Age distribution

\begin{tabular}{|c|c|}
\hline \multicolumn{2}{|c|}{ HEARING GAIN } \\
\hline $\mathrm{n}$ & 100 \\
\hline Mean & 16.24 \\
\hline Std. Deviation & 11.51 \\
\hline Minimum & 5.00 \\
\hline Maximum & 46.00 \\
\hline
\end{tabular}

statistically insignificant. (Table III)

RUT was positive in $40(65.57 \%)$ out of $61(100 \%)$ females and in $24(61.53 \%)$ out of $39(100 \%)$ males. This was compared using Chi Square test and found to be statistically insignificant. (Table IV)

Amongst $100(100 \%)$ cases $64(64 \%)$ tested RUT positive and $36(36 \%)$ tested negative. When this was analysed through an Unpaired ' $t$ ' test, it was found to be statistically significant $(\mathrm{p}<0.04)$. Helicobacter pylori could be attributed to Chronic Tonsillitis.

\section{Discussion}

Skinner et al in their study on 50 patients found that $\mathrm{H}$. pylori seropositive patients showed higher expression of positively staining macrophage and thus may have huge implication for tonsillar immune response. ${ }^{1}$

The current study compares with Ochung'o et al who studied 39 children who were diagnosed with chronic tonsillitis of which 21 were male while 18 were female. $38.5 \%$ were found to be positive for $\mathrm{H}$. pylori using RUT. ${ }^{3}$ Our studies overall prevalence rate was found to be higher than this study.

A study by Siupsinskiene et al on 97 patients divided patients into 2 groups, with chronic tonsillitis $(n=62)$ and with tonsillar hypertrophy ( $\mathrm{n}=35$; control group). They found incidence of $\mathrm{H}$. pylori was higher in the first group $(56.5 \%)$ as compared to the control group (31 $.4 \%){ }^{4}$ This was in accordance to our study suggesting prevalence of $\mathrm{H}$. pylori in chronic tonsillitis is higher.

On comparing the current study with that of Aslan, et $\mathrm{al},{ }^{5}$ who out of 52 patients found RUT positive in $22(42 \%)$ of excised mucosal tissue and $24(47 \%)$ of excised core tissue, our study results showed similar results.

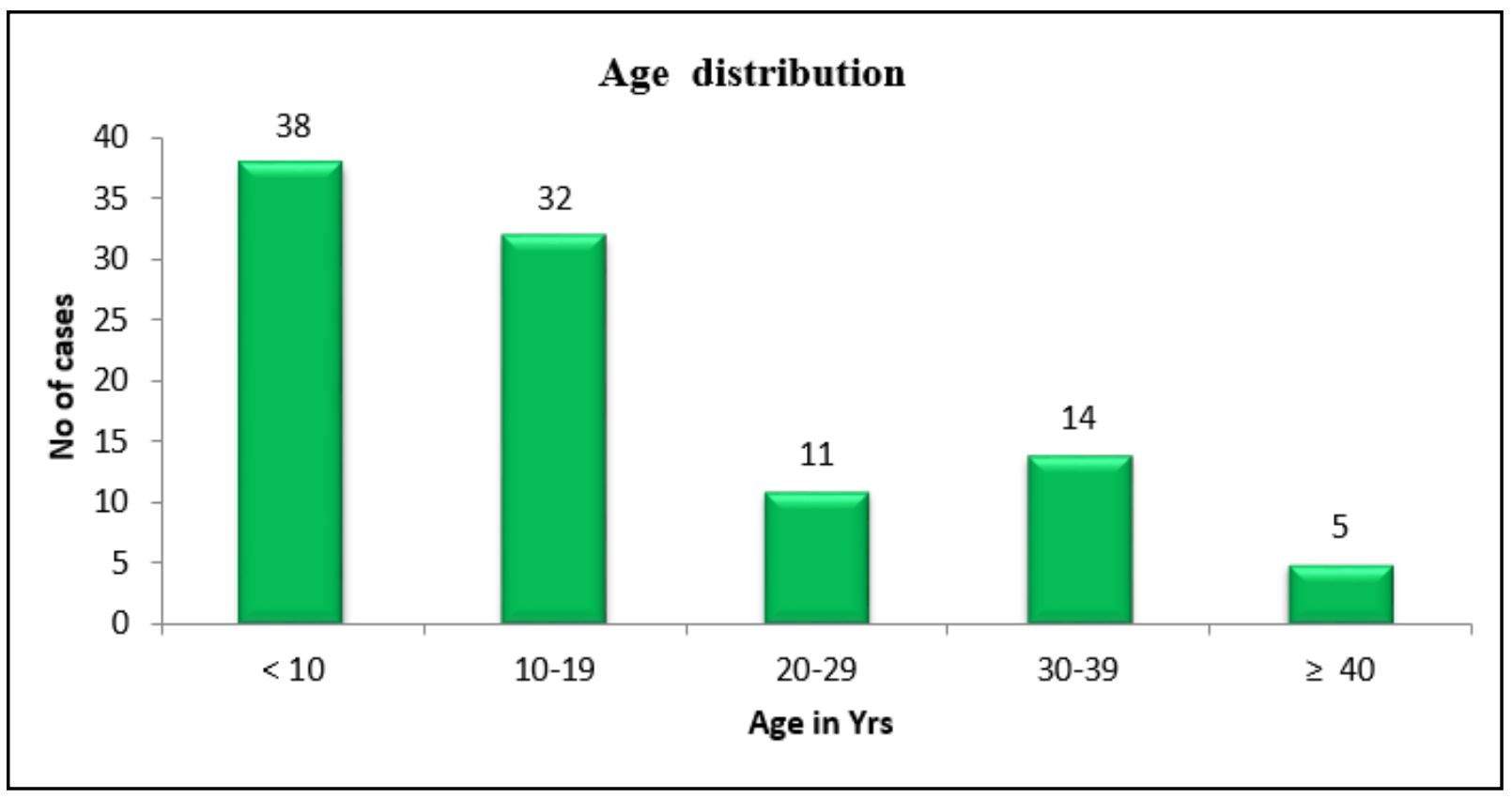

Fig. 1. Age distribution 


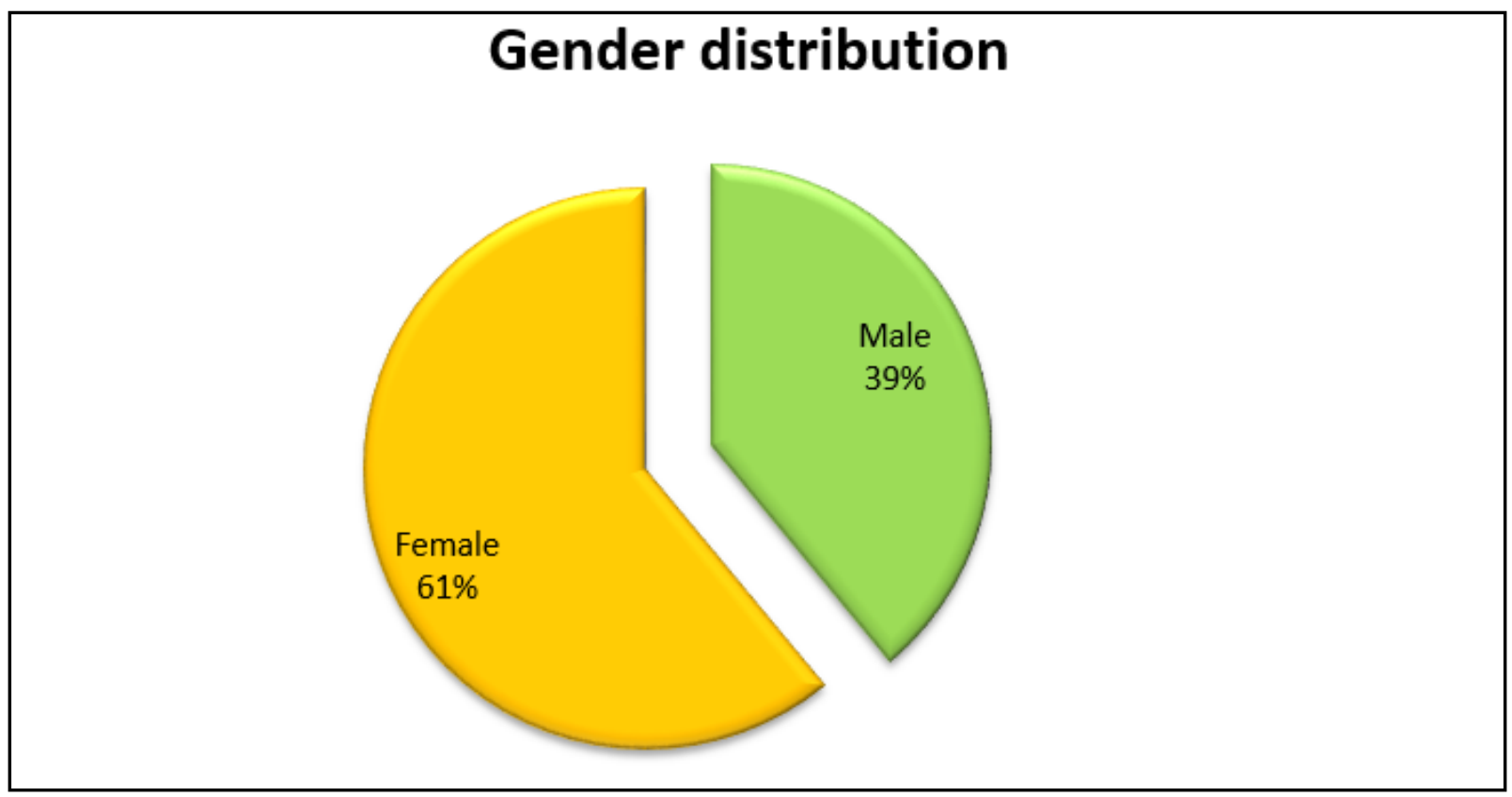

Fig. 2. Gender distribution

Table II: Results of RUT

\begin{tabular}{|c|c|c|}
\hline H. PYLORI (RUT) & FREQUENCY & PERCENT \\
\hline Positive & 64 & 64.0 \\
\hline Negative & 36 & 36.0 \\
\hline Total & 100 & 100.0 \\
\hline
\end{tabular}

Table III: Age distribution of RUT positive cases

\begin{tabular}{|c|c|c|c|}
\hline \multirow{2}{*}{ AGE (IN YEARS) } & \multicolumn{2}{|c|}{ H. PYLORI (RUT) } & CHI SQUARE \\
TEST \\
\cline { 2 - 3 } & POSITIVE (N=64) & NEGATIVE (N=36) & \multirow{2}{*}{7.26} \\
\hline $10-19$ & 26 & 12 & p=0.122 \\
\hline $20-19$ & 21 & 2 & 7 \\
\hline
\end{tabular}


Table IV: Sex-wise distribution of RUT positive cases

\begin{tabular}{|c|c|c|c|}
\hline \multirow{2}{*}{ AGE (IN YEARS) } & \multicolumn{2}{|c|}{ H. PYLORI (RUT) } & \multirow{2}{*}{$\begin{array}{c}\text { CHI SQUARE } \\
\text { TEST }\end{array}$} \\
\cline { 2 - 3 } & POSITIVE $(\mathrm{N}=64)$ & NEGATIVE (N=36) & \multirow{2}{*}{$\mathbf{p = 0 . 6 8 5}$} \\
\hline Male & 24 & 15 & \\
\hline
\end{tabular}

\section{Conclusion}

According to our study, Helicobacter pylori was found to be a common association in cases of chronic tonsillitis. It's suggested that tonsillectomy may protect the host against Helicobacter pylori infestation of the stomach. Therefore, it is plausible that Helicobacter pylori induces a pro-inflammatory reaction that is both local and systemic including in MALT tissue of Waldeyer's ring. Even after regular treatment with antibiotics the chances of getting acute infection in chronic tonsillitis still persists. Colonization of the human palatine tonsils by H.pylori is a potentially exciting new frontier which could radically alter the management approach to chronic recurrent tonsillitis. We can try treating for $\mathrm{H}$. pylori and look for any changes in incidence of tonsillitis.

\section{Financial Support:}

This research received no specific grant from any funding agency, commercial or not-for-profit sectors.

\section{Conflict(s) of Interest: None}

\section{Ethical Standards:}

"The authors assert that all procedures contributing to this work comply with the ethical standards of the relevant national and institutional guidelines on human experimentation (IEC Registration No- ECR/731/Inst/ $\mathrm{KA} / 2015$ issued under rule 122DD of the Drugs \& Cosmetics Rules 1945, Ref No- JJMMC/IEC/41-2017) and with the Helsinki Declaration of 1975, as revised in 2008."

\section{References}

1. Skinner LJ, Winter DC, Curran AJ, Barnes C, Kennedy S, Maguire AJ, et al . Helicobacter pylori and tonsillectomy. Clin. Otolaryngol. $2001 \mathrm{Jul} ; 26: 505-9$

2. John C Watkinson, Raymond W Clarke. Diseases of tonsils, tonsillectomy and tonsillotomy. In: Yogesh Bajaj, Ian Hore, editors. Scott-Brown's Otorhinolaryngology Head and Neck Surgery Volume 2. 8th ed. New York: CRC Press, Taylor \& Francis Group; 2018. p. 435-42

3. Ochung'o OP, Mugwe P, Masinde P, Waweru W. Prevalence of H.Pylori in Tonsillar Tissue of Patients with Chronic Recurrent Tonsillitis Using Rapid Urease Test in a Tertiary Referral Hospital in SubSaharan Africa. Indian J Otolaryngol Head Neck Surg. 2015 Sep; 67(3):223-6. doi:10.1007/s12070-0140754-y

4. Siupsinskiene N, Katutiene I, Jonikiene V, Janciauskas D, Vaitkus S. Helicobacter pylori in the tonsillar tissue : a possible association with chronic tonsillitis and laryngopharyngeal reflux. J Laryngol Otol. 2017 Jun; 131(6):549-56

5. Aslan S, Yilmaz I, Bal N, Sener M, Butros R, Demirhan B, Ozluoglu LN. Investigation of Helicobacter pylori in tonsillary tissue with Pronto Dry test and pathologic examination. Auris Nasus Larynx 2007; 34:339-42. 